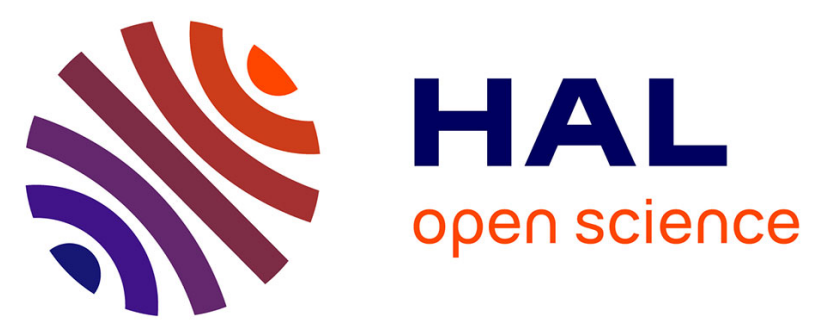

\title{
Effect of a Lignosulfonate Plasticizer on the Hydration of a Belite-Ye'elimite-Ferrite Cement Paste
}

Angélique Barneoud-Chapelier, Youssef El Bitouri, Nathalie Azéma, Gwenn Le Saout

\section{- To cite this version:}

Angélique Barneoud-Chapelier, Youssef El Bitouri, Nathalie Azéma, Gwenn Le Saout. Effect of a Lignosulfonate Plasticizer on the Hydration of a Belite-Ye'elimite-Ferrite Cement Paste. ICCM 2021 - 11th ACI/RILEM International Conference on Cementitious Materials and Alternative Binders for Sustainable Concrete, Jun 2021, En ligne, Canada. hal-03268504

\section{HAL Id: hal-03268504 https://hal.science/hal-03268504}

Submitted on 23 Jun 2021

HAL is a multi-disciplinary open access archive for the deposit and dissemination of scientific research documents, whether they are published or not. The documents may come from teaching and research institutions in France or abroad, or from public or private research centers.
L'archive ouverte pluridisciplinaire HAL, est destinée au dépôt et à la diffusion de documents scientifiques de niveau recherche, publiés ou non, émanant des établissements d'enseignement et de recherche français ou étrangers, des laboratoires publics ou privés. 


\title{
Effect of a Lignosulfonate Plasticizer on the Hydration of a Belite-Ye'elimite-Ferrite Cement Paste
}

\author{
Angélique Barneoud-Chapelier, Youssef El Bitouri, Nathalie Azéma, Gwenn Le Saout* \\ LMGC, IMT Mines Ales, Univ Montpellier, CNRS, Ales, France \\ *Corresponding author: gwenn.le-saout@mines-ales.fr / +33466785312
}

\begin{abstract}
Belite-Ye'elimite-Ferrite (BYF) cements have been recently developed in order to substitute ordinary Portland cement (OPC), as they release up to $30 \%$ less $\mathrm{CO}_{2}$ and their performances tend to be similar. This work aims to give a first insight and understanding on the influence of a lignosulfonate plasticizer (LS) on the hydration and the properties of a BYF cement paste. For this purpose, hydration of neat cement paste $(\mathrm{w} / \mathrm{c}=0.4)$ was followed by isothermal calorimetry associated with in situ XRD for the first 4 hours. In addition, plasticizer adsorption was investigated using TOC measurements. Rheological and compressive strength tests were also performed. The results showed that LS changes the hydration kinetics, modifying both induction period (that becomes shorter for low dosage and longer for higher dosage) and rate of ettringite precipitation. For all dosages used, LS decreases the heat of hydration and the compressive strength in the first day. Also, its impact on particle surfaces improves their dispersion and causes a diminution of the shear stress of cement paste, allowing better workability.
\end{abstract}

Keywords: Adsorption, belite ye'elimite ferrite (BYF) cement, lignosulfonate, yield stress 
Angélique Barneoud-Chapelier is a PhD student at IMT Mines Alès. She has a Master degree in chemistry of solids and materials currently works on the effect of admixtures on BYF cement pastes.

Youssef El Bitouri is an Associate Professor at IMT Mines Alès. His research concerns the fresh behavior of cement based materials, and the effect of the fresh behavior on durability and mechanical properties.

Nathalie Azéma is a Professor at IMT Mines Alès. Her research contributes, by a multiscale experimental approach of characterization (mainly optical methods), to have a better understanding and control of dispersion and stabilization of mineral suspensions (as cement pastes in the presence (or not) of mineral additives and/or adjuvants), with a focus on the mesoscopic scale.

Gwenn Le Saout is a Professor at IMT Mines Alès. His research interest includes the comprehension of hydration mechanisms of cements with or without supplementary cementitious materials. His work is focused by a goal to improve the characterization of cementitious materials and the study of hydration using a multi techniques as well as thermodynamic approaches.

\section{INTRODUCTION}

Cement industry is responsible for $8 \%$ of global $\mathrm{CO}_{2}$ emissions ${ }^{1}$, mainly due to portland cement production. In order to reduce them, new binders are developed such as Belite-Ye'elimite-Ferrite (BYF) cements, of which the production releases up to $30 \%$ less $\mathrm{CO}_{2}{ }^{2,3}$. Such cements are proposed as alternative to portland cement ${ }^{4}$.

The three main phases they contain are, in the order of content: belite $\left(\mathrm{C}_{2} \mathrm{~S}\right.$, cement notation will hereafter be used: $\mathrm{C}=\mathrm{CaO}, \mathrm{S}=\mathrm{SiO}_{2}, \mathrm{~A}=\mathrm{Al}_{2} \mathrm{O}_{3}, \mathrm{~F}=\mathrm{Fe}_{2} \mathrm{O}_{3}, \breve{\mathrm{S}}=\mathrm{SO}_{3}, \mathrm{H}=\mathrm{H}_{2} \mathrm{O}$ ), ye'elimite $\left(\mathrm{C}_{4} \mathrm{~A}_{3} \breve{\mathrm{S}}\right)$ and ferrite $\left(\mathrm{C}_{4} \mathrm{AF}\right)$. Calcium sulfate is added to react with ye'elimite to form ettringite and to enhance mechanical strength, usually in larger amounts than in portland cement (up to $25 \%$ ). Previous studies of the BYF hydration have shown the different hydration steps. During the first hours, only ye'elimite and calcium sulfate hydrate react, to form ettringite and aluminium hydroxide $^{5}$ (usually poorly crystallized ${ }^{6-8}$ ) (1). Then, the local concentration of sulfate decreases ${ }^{9}$ as they react to form AFm (2). Due to its high reactivity, the conversion rate of ye'elimite can reach $85 \%$ in 6 hours $^{7}$.

$$
\begin{aligned}
& \mathrm{C}_{4} \mathrm{~A}_{3} \breve{\mathrm{S}}+2 \mathrm{CS}+38 \mathrm{H} \rightarrow \mathrm{C}_{3} \mathrm{~A} \cdot 3 \mathrm{CS} \cdot 32 \mathrm{H}+2 \mathrm{AH}_{3} \\
& \mathrm{C}_{4} \mathrm{~A}_{3} \breve{\mathrm{S}}+18 \mathrm{H} \rightarrow \mathrm{C}_{3} \mathrm{~A} \cdot \mathrm{CS} \cdot 12 \mathrm{H}+2 \mathrm{AH}_{3}
\end{aligned}
$$


Afterwards, when the sulfate concentration in the interstitial liquid becomes low enough ${ }^{9}$, belite begins to hydrate. This leads to the formation of strätlingite $\left(\mathrm{C}_{2} \mathrm{ASH}_{8}\right)$, siliceous hydrogarnet $\left(\mathrm{C}_{3} \mathrm{SH}_{4}\right.$ like $)$, and possibly C-S-H. The hydration of ferrite in theses cements has not yet well been elucidated, it is suspected to react in the same time as both belite ${ }^{9,10}$ or ye'elimite ${ }^{11-14}$.

The hydration of BYF cements remains complex; various experiments and thermodynamic modelling were performed for ye'elimite-containing cements to understand their hydration. However, the number of studies on the effect of admixtures on this kind of cement remains limited $^{15,16}$, while a lot of data is available concerning the hydration of portland cement cement in the presence of admixtures ${ }^{17,18}$. Lignosulfonate plasticizers (LS) are one type of such admixtures. They are sulfonated wood extracts that have been widely used in order to increase the concrete workability while diminishing the amount of water ${ }^{19,20}$. Our work deals with the effect of a lignosulfonate plasticizer on the hydration and properties of a BYF cement paste. The effect of LS at early age on microstructure and kinetics was investigated using in-situ XRD and isothermal calorimetry. Some compressive strength tests were performed to evaluate the effects until 28 days of hydration. In addition, the LS consumption by the cement particles at the early age was quantified thanks to TOC measurements, and rheological measurements allowed the evaluation of the flowability of the cement pastes

\section{MATERIAL AND METHODS}

\section{Material}

The cement used in this study was obtained by powder mixing of BYF clinker with $10 \%$ natural anhydrite. Its granular properties are given in Table 1, as well as its elemental and mineral composition. The oxide content was determined by XRF, and the mineral content was determined by Rietveld quantitative X-ray powder diffraction. A commercial hardwood calcium lignosulfonate (LS) is used as plasticizer. A hardwood calcium lignosulfonate (LS) was used as plasticizer. Its mass weighted molecular weight $\mathrm{Mw}$ was $6400 \mathrm{~g} / \mathrm{mol}$ and the number weighted molecular weight (Mn) was $500 \mathrm{~g} / \mathrm{mol}$, giving dispersity equal to 12.8 . The content of reducing sugar is $14.8 \%$ based on dry mass.

Its dosage is expressed as LS-to-cement mass ratio, and was chosen to be in the same order of magnitude as usually used in portland cement (i.e. from 0 to $0.5 \%$ ). Calorimetry test was performed with a dosage of $0.7 \%$ LS to better exhibit the retarding effect, and adsorption tests were performed with a dosage up to $1 \%$ to explore saturation effects.

Cement pastes were prepared with water-to-cement ratio $(\mathrm{w} / \mathrm{c})$ of 0.4 , by pouring cement into deionized water containing the appropriate amount of LS (corresponding to time zero of hydration), 
while stirring at $500 \mathrm{rpm}$ for $1 \mathrm{~min}$ and then for a further minute at $1000 \mathrm{rpm}$ with a Stuart SS30 overhead stirrer. For interstitial liquid extraction, $5 \mathrm{~min}$ before centrifugation, paste was stirred at $1000 \mathrm{rpm}$ for $20 \mathrm{~s}$ and then $2000 \mathrm{rpm}$ for $10 \mathrm{~s}$. Samples were cured at $25^{\circ} \mathrm{C}\left[77^{\circ} \mathrm{F}\right]$ and $86 \pm 3 \%$ relative humidity on the first day of hydration in order to limit the drying of the samples, and then stored in tap water.

\section{Methods}

\section{Isothermal calorimetry}

The heat of hydration was followed at $25^{\circ} \mathrm{C}\left[77^{\circ} \mathrm{F}\right]$ by introducing $5 \mathrm{~g}[0.177 \mathrm{oz}]$ of paste in a TAM Air isothermal micro-calorimeter, using a glass ampoule.

\section{In-situ XRD}

In situ XRD measurements were made on hydrating cement pastes, with Kapton cover to avoid water evaporation. Data were collected from $5^{\circ}$ to $50^{\circ}(2 \theta)$ during $17.5 \mathrm{~min}$ for the firsts 4 hours of hydration. Patterns were recorded on a Bruker AXS D8 advanced with a $\mathrm{CuK} \alpha$ radiation.

\section{Rheological measurements}

Rheological measurements were carried out using an experimental AR 2000ex rheometer (TA Instruments), equipped with parallel-plate geometry covered with sand paper. The measurement procedure consists of a pre-shear phase (during $80 \mathrm{~s}^{\text {a }} 100 \mathrm{~s}^{-1}$ ) followed by decreasing shear rate ramp (from $100 \mathrm{~s}^{-1}$ to $0.1 \mathrm{~s}^{-1}$ ). Due to the complexity of obtaining the steady state, for each shear rate, the shear stress was measured at a similar equilibrium time of $20 \mathrm{~s}$ for all cement pastes. The dynamic yield stress was determined by extrapolating the Herschel-Bulkley model.

\section{Consumed plasticizer}

The amount of consumed LS by the cement is the difference between initial amount of LS added in the mixing water and LS remaining in interstitial solution. This remaining amount was determined after its extraction by centrifugation of the paste $(10000 \mathrm{rpm}$ for $5 \mathrm{~min})$, filtration $(0.45 \mu \mathrm{m})$, dilution with milli-Q water and nitric acid to avoid hydrates formation. It was determined using vario TOC Cube (elementar) in total carbon mode, by considering that the only carbon present in the solution is due to the LS.

\section{Compressive strength}

Compressive strengths were tested on $20 \times 20 \times 20 \mathrm{~mm}$ [20 mm $=0.787 \mathrm{in}$.] samples. Special molds consisting of $\mathrm{ABS} 3 \mathrm{D}$ printed were used to elaborate the cement paste samples. The compressive strength tests were carried out on a MTS press using force control with a loading rate of $0.1 \mathrm{MPa} / \mathrm{s}$. 


\section{RESULTS AND DISCUSSION}

\section{Effect of the LS on the early age hydration}

To explain the early age hydration mechanisms of the paste without and with $0.1 \%$ LS, the phase composition in relation with the heat flow was determined thanks to in-situ XRD measurements. As shown in Fig. 1a, the first calorimetry peak corresponds to the first dissolution of ye'elimite and anhydrite, the latter forming gypsum as an intermediate. Also, precipitation of ettringite according to (1) seems to start immediately. After a short period when the heat flow decreases, at 1 hour of hydration, a slight acceleration in the dissolution of anhydrite, ye'elimite and ferrite happens, in accordance with stronger precipitation of ettringite. After 2 hours of hydration, the most intense heat flow peak is observed. It corresponds to even stronger dissolution of ferrite and ye'elimite, leading not only to the formation of ettringite but also to the first precipitation of monosulfoaluminate according to (2). The width of the XRD peaks of the latter suggests it is poorly crystallized (not shown). At the end of this third peak, the dissolution of anhydrous particles seems to decelerate.

With the addition of $0.1 \%$ LS (Fig. 1b), at the beginning of hydration anhydrite also dissolves immediately to form gypsum, but in higher amounts and remains longer in the cement paste. Ettringite is not detected before $40 \mathrm{~min}$ of hydration. Indeed, ye'elimite and ferrite start to dissolve at the same time as gypsum, thereby provoking ettringite first precipitation according to (1). After $1.5 \mathrm{~h}$ of hydration, gypsum totally dissolves concomitantly with a significant dissolution of ye'elimite and ferrite. At the same time, a strong acceleration of ettringite precipitation is observed, even stronger than observed without LS. At 2 hours of hydration, monosulfoaluminate starts to precipitate, with a diminution of the precipitation rate of ettringite, sign of the start of sulfate depletion and leading to the third calorimetry peak.

Moreover, the released heat flow of the paste containing gradual amounts of LS was measured; curves are presented in Fig. 2. It was calculated from 1 hour of hydration in order to avoid the effect of the introduction of the sample in the calorimeter. For all dosages, two effects of the LS can be observed: it modifies the time of the "induction period", and changes the hydration rate. Indeed, for low dosages $(0.05 \%$ and $0.1 \%)$, the induction period is shorter, and the heat increase due to the higher ettringite precipitation rate is more intense. These results agree with previous studies that showed ettringite formation is enhanced by LS addition in OPC ${ }^{21-23}$. For higher dosages $(>0.1 \%)$, the induction period is extended, and the heat increase suggests a higher ettringite precipitation rate. Finally, from $0.4 \%$ LS, the curve seems flattened, showing a greater retardation of the hydration and the heat release is decomposed in two steps. 
It also has to be noted that the heat release at 20 hours is decreased by the addition of LS, and equivalent for all dosages, suggesting a modification of the phase assemblage from the early age hydration due to the retardation.

\section{Effect of LS on dispersion and rheological properties at early age}

The purpose of adding plasticizer to cement based materials is to improve the workability. Yield stress turns out to be a relevant parameter to study the effect of plasticizer ${ }^{24}$ since it corresponds to the energy required to initiate flow. It is known that lignosulfonates acts by electrosteric effect to better disperse the cement particles ${ }^{25}$. The dynamic yield stress as a function of LS dosage is presented in Fig. 3. The results show that LS drastically decreases the yield stress from 0 to $0.2 \%$ LS. Moreover, cement pastes don't display any yield stress from LS dosage of about $0.2 \%$. It can be noted that despite the fact that the yield stress becomes negligible, cement pastes conserve a shear thinning behavior .

The consumption of LS was quantified by TOC measurements. Fig. 4a shows the consumption isotherm. The consumption of the LS is proportional to the amount of LS added to the cement, and does not seem to decelerate at high dosage (un to $1 \%$ ). Also, only $65 \%$ to $72 \%$ of LS is consumed, showing a relatively good affinity between LS and the particles, as well as a good solubility with the interstitial liquid.

Moreover, the consumption was measured at different hydration time when $0.1 \%$ and $0.5 \%$ LS were added; results are presented in Fig. 4b. As expected, more LS is consumed for $0.5 \%$ LS. Also, for both dosages, consumption slightly increases with time until 90 min of hydration, suggesting interaction not only with anhydrous particles, but also with the hydrates slowly formed for these hydration times.

Yield stress is decreased with the LS content and reduced near zero at $0.2 \%$ thanks to plasticizer adsorption onto the solid particles, which induces electrosteric effect. At $0.2 \%$, we can also observe an increase in the induction period whereas a slight acceleration was noticed at lower dosage. This is consistent with the mechanism proposed by Marchon et al. ${ }^{26}$ in the case of a direct addition of PCE with a portland cement. At low dosage $(<0.2 \%)$, SPs are mainly consumed by ettringite formation. Indeed, the surface of ettringite has the highest surface potential which allows the preferential adsorption of negatively charged molecules like superplasticizers ${ }^{27,28}$. This does not delay the main hydration peak. In the present study, it would cause a slight acceleration. At higher dosages, the SPs also adsorb on the main anhydrous phase, hindering its dissolution and resulting in a longer induction period. This LS adsorption on both hydrated and unhydrated phases also reduced the yield stress to zero. 
After the induction period, ettringite formation is faster when LS is added, which is consistent with the observations of Bishop and Barron ${ }^{29}$; they showed that both sucrose and lignosulfonate enhance ettringite formation. They suggested that lignosulfonates have the ability to template ettringite formation, explaining the catalysis of its growth.

\section{Effect of LS on the hydration at later ages}

Fig. 5 shows the evolution of the compressive strength on the first 28 days of the cement paste containing $0,0.1$ and $0.5 \%$ LS. At least over the seven first days, the compressive strength slightly decreases with the amount of LS added, and doesn't seem to evolve with time. This suggests that the only hydration reactions happening in the first day, and that the change in hydration kinetics earlier discussed has an impact on the cement strength. At 28 days of hydration, even if the addition of $0.5 \%$ LS to the cement still reduces the compressive strength, the sample with $0.1 \%$ LS shows similar strength when compared with the one without LS. It can be hopped that when belite will further react, the improved dispersion of the particles enhances belite reactivity at later ages.

\section{CONCLUSIONS}

The investigation on the effect of a LS plasticizer on a BYF cement paste showed two main effects on its hydration. The first effect is related to the induction period: at low dosage of LS, the induction period decreases, while at high dosage, an increase of the induction period is observed. The second effect concerns the rate of ettringite precipitation which increases in the presence of LS. On the other hand, LS was found to have a good affinity with the surface of the particles, enhancing their dispersion and their fluidity. The modification of the hydration which results in the decrease of the heat of hydration at 20 hours, and a decrease of compressive strength during the first week of hydration is expected to be due to the adsorption of LS. Further works are needed to better understand the mode of action of LS on BYF cement hydration; notably the phase composition will be followed at longer times, and studies will be lead on BYF cements of different compositions.

\section{AKNOLEDGEMENTS}

The authors would like to thank LafargeHolcim for providing the clinker and natural anhydrite, and Borregaard for providing the lignosulfonate plasticizer. Blandine Albert (LafargeHolcim) and Rolf Andreas Lauten (Borregaard) are acknowledged for their relevant remarks on this work.

\section{REFERENCES}

1. Olivier, J. G. J. (PBL)., Janssens-Maenhout, G. (EC-J., Muntean, M. (EC-J., et al. "Trends in Global CO2 Emissions: 2016 Report," PBL Netherlands Environmental Assessment Agency \& European Commission's Joint Research Centre (JRC), 2016, p. 86. 
2. Gartner, E., and Sui, T. "Alternative cement clinkers," Cement and Concrete Research, 2017.

3. Sharp, J. H., Lawrencef, C. D., and Yang, R. "Calcium sulfoaluminate cements - lowenergy cements , special cements or what?," Advances in Cement Research, V. 11, No. 1, 1999, pp. 3-13.

4. Quillin, K., Dunster, A., Tipple, C., et al. "Project AETHER Testing the durability of a lower-CO2 alternative to Portland cement." 34th Annual Cement \& Concrete Science Conference. 2014.

5. Cuesta, A., Álvarez-Pinazo, G., Sanfélix, S. G., et al. "Hydration mechanisms of two polymorphs of synthetic ye'elimite," Cement and Concrete Research, V. 63, 2014, pp. 12736.

6. Álvarez-Pinazo, G., Cuesta, A., García-Maté, M., et al. "In-situ early-age hydration study of sulfobelite cements by synchrotron powder diffraction," Cement and Concrete Research, V. 56, 2014, pp. 12-9.

7. Morin, V., Walenta, G., Gartner, E., et al. "Hydration of a Belite-Calcium SulfoaluminateFerrite cement : Aether TM." 13th International Congress on the Chemistry of Cement. 2011. pp. 1-7.

8. Li, G. S., Walenta, G., and Gartner, E. M. "Formation and Hydration of Low-CO 2 Cements Based on Belite, Calcium Sulfoaluminate and Calcium Aluminoferrite," 12th International Congress on the Chemistry of Cement., No. November 2015, 2007.

9. Wang, J. "Hydration mechanism of cements based on low-CO2 clinkers containing belite, ye'elimite and calcium alumino-ferrite." Université Lille 1, 2010.

10. Álvarez-Pinazo, G., Santacruz, I., Aranda, M. A. G., et al. "Hydration of belite-ye'elimiteferrite cements with different calcium sulfate sources," Advances in Cement Research, V. 28, No. 8, 2016, pp. 529-43.

11. Álvarez-Pinazo, G., Santacruz, I., León-Reina, L., et al. "Hydration Reactions and Mechanical Strength Developments of Iron-Rich Sulfobelite Eco-cements," Industrial \& Engineering Chemistry Research, V. 52, No. 47, 2013, pp. 16606-14.

12. Fukuhara, M., Goto, S., Asaga, K., et al. "Mechanisms and kinetics of C4AF hydration with gypsum," Cement and Concrete Research, V. 11, No. 3, 1981, pp. 407-14.

13. Möschner, G., Lothenbach, B., Winnefeld, F., et al. "Solid solution between Al-ettringite and Fe-ettringite," Cement and Concrete Research, V. 39, No. 6, 2009, pp. 482-9.

14. Meller, N., Hall, C., Jupe, A. C., et al. "The paste hydration of brownmillerite with and without gypsum : a time resolved synchrotron diffraction study at 30 , 70, 100 and $150 \mathrm{u} \mathrm{C,"}$ 2004.

15. Zajac, M., Skocek, J., Bullerjahn, F., et al. "Effect of retarders on the early hydration of calcium-sulpho-aluminate (CSA) type cements," Cement and Concrete Research, V. 84, 2016, pp. 62-75.

16. Ma, B., Ma, M., Shen, X., et al. "Compatibility between a polycarboxylate superplasticizer and the belite-rich sulfoaluminate cement: Setting time and the hydration properties," Construction and Building Materials, V. 51, 2014, pp. 47-54.

17. He, Z., Shen, A., Guo, Y., et al. "Cement-based materials modified with superabsorbent polymers: A review," Construction and Building Materials, V. 225, 2019, pp. 569-90.

18. Marchon, D., and Flatt, R. J. "Impact of chemical admixtures on cement hydration." In: 
Aïtcin, P.-C., Flatt, R. J., eds. Science and Technology of Concrete Admixtures. Elsevier, 2016. pp. 279-304.

19. Gargulak, J. D., and Lebo, S. E. "Commercial use of lignin-based materials," $A C S$ Symposium Series, V. 742, No. Figure 1, 1999, pp. 304-20.

20. Arel, H. Ş., and Aydin, E. "Effects of Ca-, Mg-, K-, and Na-lignosulfonates on the behavior of fresh concrete," Construction and Building Materials, V. 157, 2017, pp. 1084-91.

21. Colombo, A., Geiker, M., Justnes, H., et al. "The effect of calcium lignosulfonate on ettringite formation in cement paste," Cement and Concrete Research, V. 107, No. January, 2018, pp. 188-205.

22. Bishop, M., and Barron, A. R. "Cement hydration inhibition with sucrose, tartaric acid, and lignosulfonate: Analytical and spectroscopic study," Industrial and Engineering Chemistry Research, V. 45, No. 21, 2006, pp. 7042-9.

23. Danner, T., Justnes, H., Geiker, M., et al. "Phase changes during the early hydration of Portland cement with Ca-lignosulfonates," Cement and Concrete Research, V. 69, 2015, pp. $50-60$.

24. Paulini, P. "Reaction mechanisms of concrete admixtures," Cement and Concrete Research, V. 20, No. 6, 1990, pp. 910-8.

25. Kauppi, A., Andersson, K. M., and Bergström, L. "Probing the effect of superplasticizer adsorption on the surface forces using the colloidal probe AFM technique," Cement and Concrete Research, V. 35, No. 1, 2005, pp. 133-40.

26. Marchon, D., Juilland, P., Gallucci, E., et al. "Molecular and submolecular scale effects of comb-copolymers on tri-calcium silicate reactivity: Toward molecular design," Journal of the American Ceramic Society, V. 100, No. 3, 2017, pp. 817-41.

27. Plank, J., and Hirsch, C. "Impact of zeta potential of early cement hydration phases on superplasticizer adsorption," Cement and Concrete Research, V. 37, No. 4, 2007, pp. 53742 .

28. Zingg, A., Winnefeld, F., Holzer, L., et al. "Adsorption of polyelectrolytes and its influence on the rheology, zeta potential, and microstructure of various cement and hydrate phases," Journal of Colloid and Interface Science, V. 323, No. 2, 2008, pp. 301-12.

29. Bishop, M., and Barron, A. R. "Cement Hydration Inhibition with Sucrose, Tartaric Acid, and Lignosulfate: Analytical and Spectoscopic Study," Industrial Eng. Chem. Res., V. 45, No. 21, 2006, pp. 7042-9. 
Table 1- Granular and chemical properties of the BYF cement used $[1 \mathrm{~g}=0.0353 \mathrm{oz}, 1 \mathrm{~m}=3.281 \mathrm{ft}]$

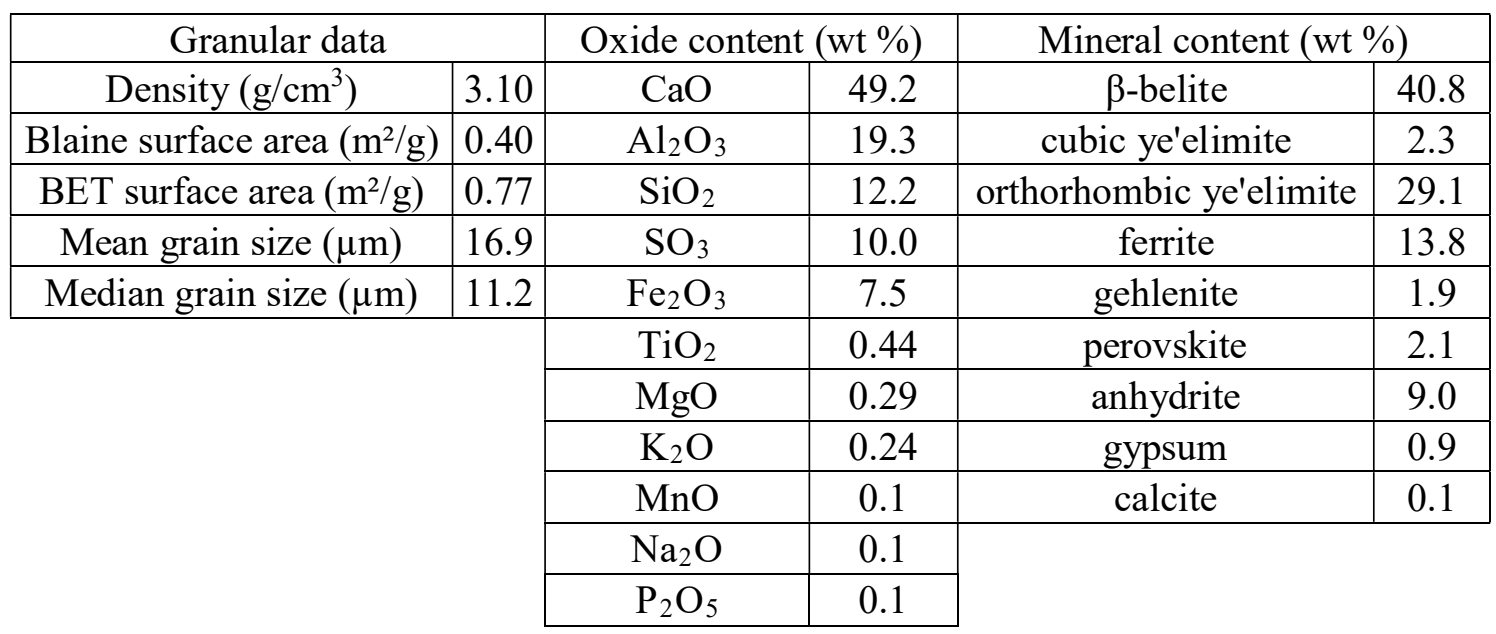

a)

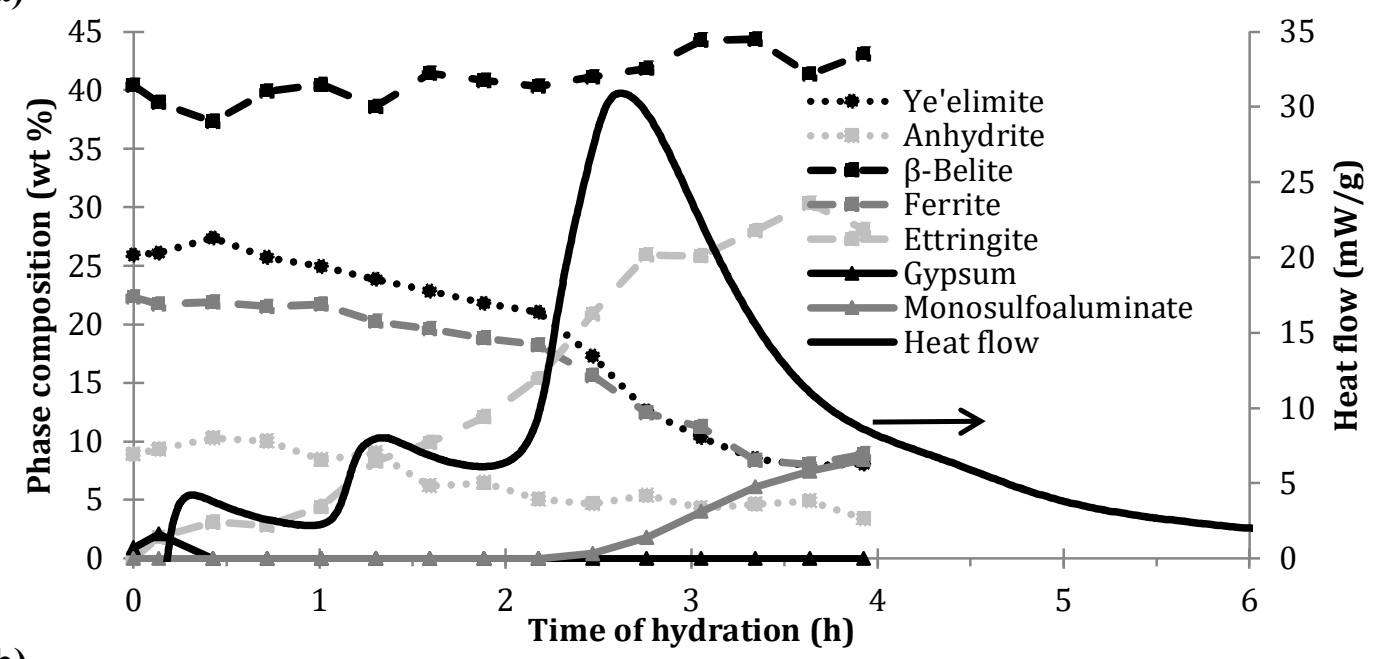

b)

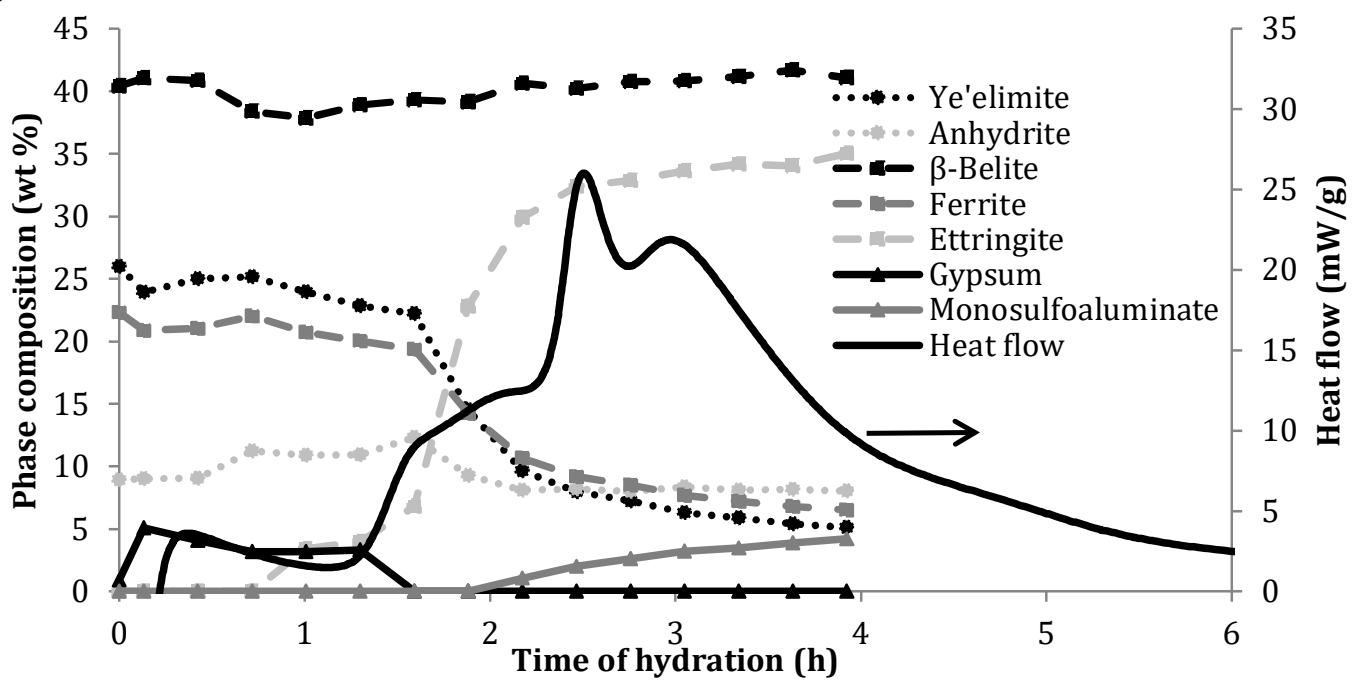

Fig. 1-Mineralogical composition and heat flow evolution with time of the cement paste a) without admixture and b) with $0.1 \%$ LS added. Only tendencies (not absolute values) should be taken into account 


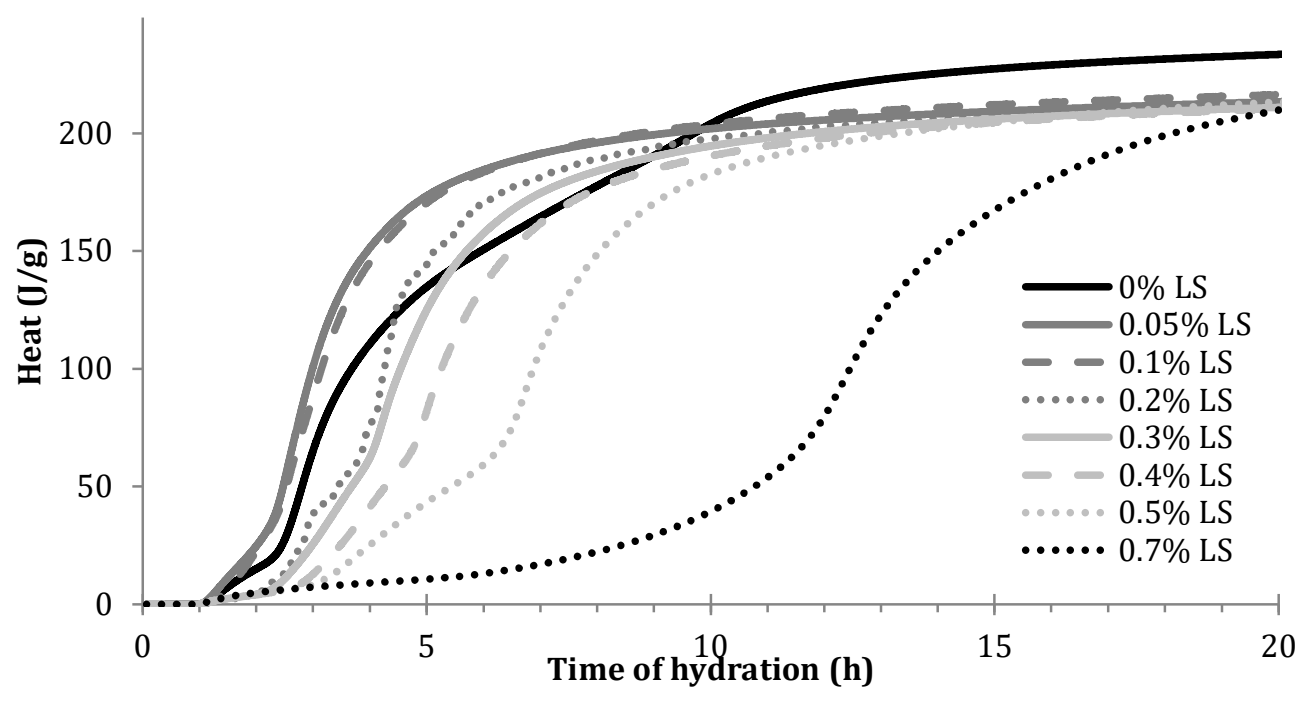

Fig. 2-Heat of hydration at $25^{\circ} \mathrm{C}\left[77^{\circ} \mathrm{F}\right]$ of the cement paste with different additions of LS

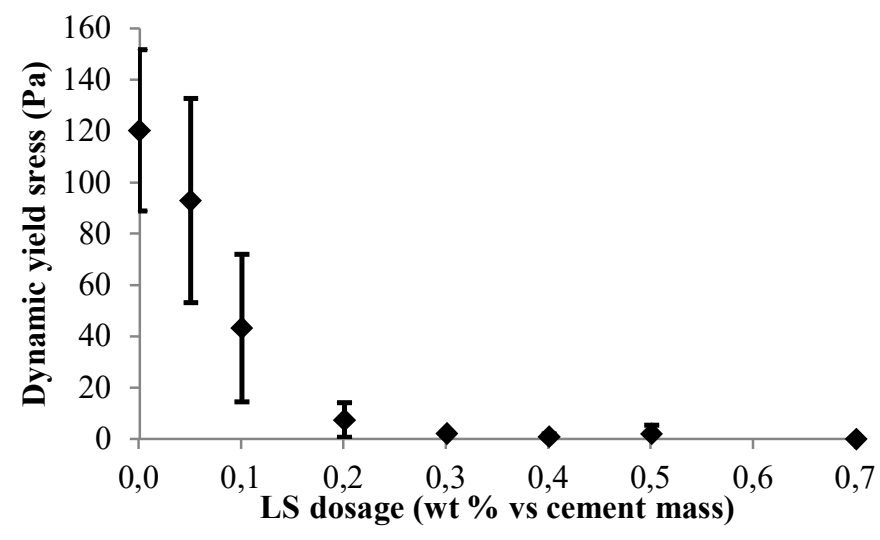

$\left[1 \mathrm{~Pa}=145.0310^{-6} \mathrm{psi}\right]$

Fig. 3-Dynamic yield stress of the paste at 5 min of hydration, with different amounts of LS added

a)
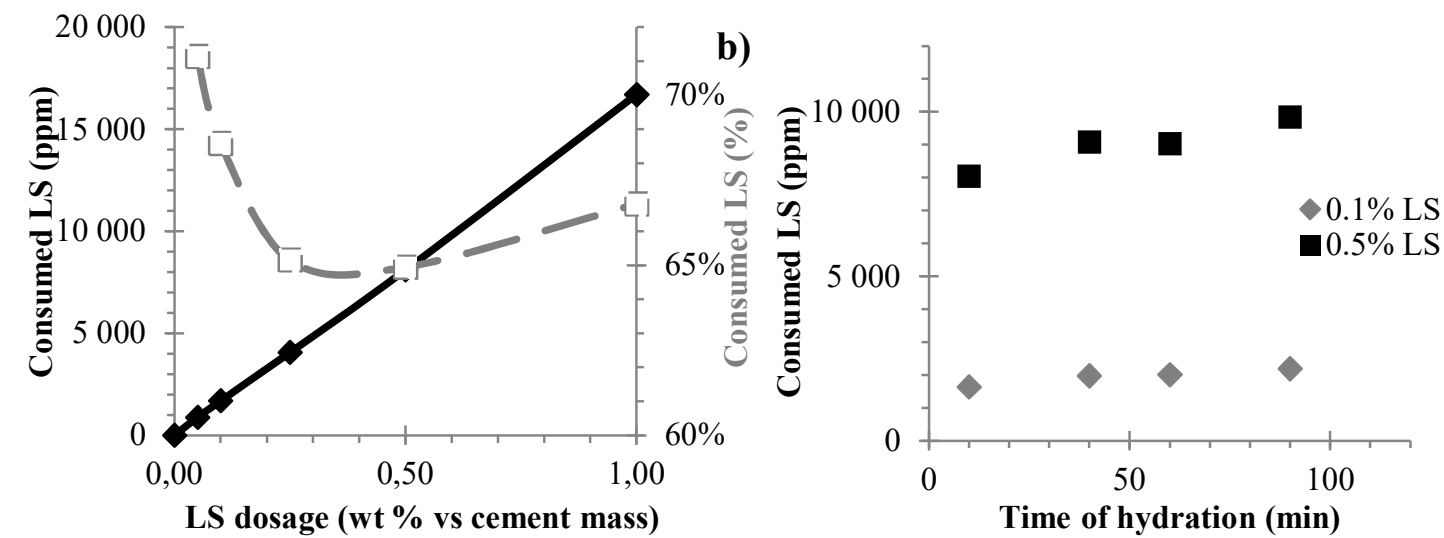

Fig. 4-LS consumption by the cement particles a) at $10 \mathrm{~min}$ hydration for different LS dosage b) with time for $0.1 \%$ and $0.5 \%$ LS 


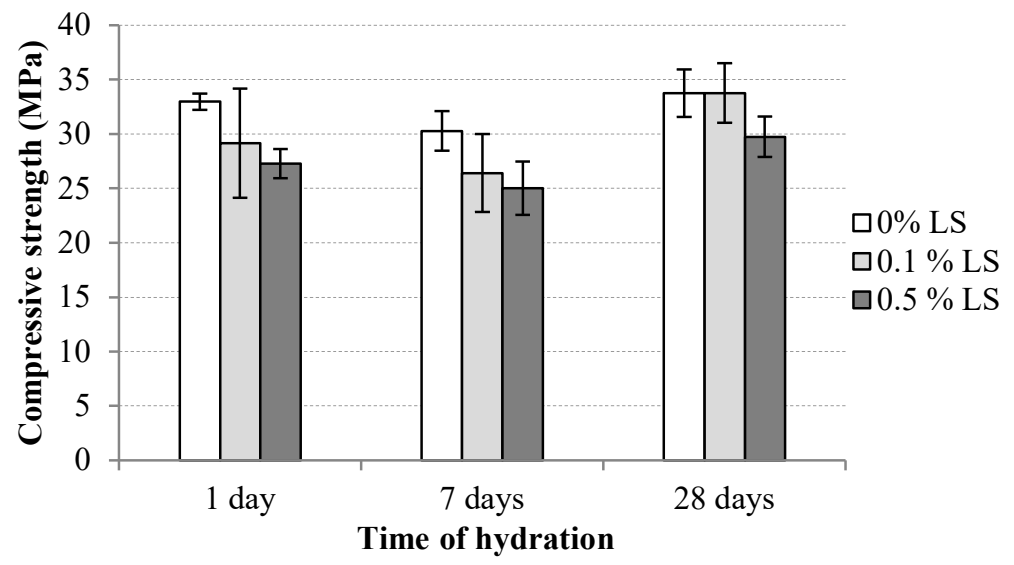

$[1 \mathrm{MPa}=0.145 \mathrm{psi}]$

Fig. 5-Compressive strength of the cement paste with different LS dosages 